\title{
Cerebellar culmen-substantia nigra tract assisted rehabilitation post stroke: a case report
}

\author{
Ishida Tetsuro 1, 2 *, Murayama Tomonori 3, 4
}

\begin{abstract}
${ }^{1}$ Department of Psychiatry, Hokujinkai ISHIBASHI Hospital, Nagahashi, Otaru, Japan.
${ }^{2}$ Department of Neuropsychiatry School of Medicine, Sapporo Medical University, Chuo-ku, Sapporo, Japan.

${ }^{3}$ Graduate school of Medicine, Sapporo Medical University, Chuo-ku, Sapporo, Japan.

${ }^{4}$ Department of Psychiatry, Kushiro Red Cross Hospital, Shinei-cho, Kushiro, Japan.

*Corresponding author: Ishida Tetsuro. Ishibashi Hospital 3-7-7-Nagahashi. Zip Code: 047-0036-Japan. Phone: +81-134-25-6655. E-mail: teturoisida@yahoo.co.jp.
\end{abstract}

Research Ethics Committee Approval (if necessary): We declare that the patient approved the study by signing an informed consent form and the study followed the ethical guidelines established by the Declaration of Helsinki.

Received on: Dec 28, 2021. Accepted on: Jan 11, 2022. Available online: Jan 16, 2021.

Abstract
An 88-year-old right-handed man was admitted to our hospital for cognitive
impairment and right-sided paralysis. His head non-contrast computed tomography
(CT) showed large low-density areas (LDA) and fibrous structures in the left occipital
and temporal lobe regions. Despite the fact that it had been more than 10 years since
his stroke, rehabilitation was effective. This is a rare case in which cerebellar culmen -
substantia nigra tract assisted rehabilitation after stroke.
Keywords: cerebellar culmen, substantia nigra, tract, stroke, rehabilitation

\section{Introduction}

Early start of rehabilitation is necessary in the treatment of paralysis after stroke. It is effective only within a few weeks to a few months, and its effectiveness is limited beyond one year. However, it has been suggested that the duration is also affected by individual differences due to genetic variations and neuroplasticity [1].
If these factors were properly assessed, rehabilitation would be more appropriately carried out and the quality of life of patients after stroke would be much improved. This is particularly good news for patients who have not previously received adequate rehabilitation because they have been considered unlikely to improve further.

The purpose of the study is to identify the factors that make post- 
Cerebellar culmen-substantia nigra tract assisted rehabilitation post stroke: a case report

stroke patients more likely to benefit from rehabilitation, based on their imaging findings.

\section{Case report}

An 88-year-old right-handed man was admitted to our hospital for cognitive impairment and right-sided paralysis. He had suffered a stroke 14 years ago and received life-saving treatment. He survived, but paralysis appeared on the right side of his body. However, he refused to undergo rehabilitation.

He lives alone with his sickly wife and was discharged early as he wanted to continue caring for her. Eight years ago, he showed cognitive declines, but his wife's niece who lives nearby supported their life. One year ago, his wife died and he also suffered from pneumonia. So, he was admitted to the respiratory department of another hospital.

After the pneumonia treatment was completed, he was admitted to our hospital for rehabilitation. When he was admitted, his Mini Mental State Examination (MMSE) showed 4/30 points. He was diagnosed as vasculares dementia (VaD). The degree of his paralysis was rated as scale 5 stablished by modified Rankin Scale (mRS) [2].

He could not stand up, so he had to crawl to get around and could not eat on his own. Although, he was not blind, he often did not notice us when we stood in front of him and recognized us only after we called him. This symptom may have been indicative of his visual apraxia or impaired attention function.

He was angry, often throwing tantrums and yelling over trivial matters. Blood tests, electrocardiogram (ECG) and electroencephalogram (EEG) showed no abnormal findings. This symptom may have been indicative of his visual apraxia or impaired attention function. Blood tests, electrocardiogram and electroencephalogram showed no abnormal findings. His head noncontrast computed tomography (CT) showed not only large LDAs in the left occipital and temporal lobe regions, but also fibrous structures connecting the cerebellar culmen to the substantia nigra (Figure 1).

After admission, the patient was started on $5 \mathrm{mg}$ of memantine and rehabilitation with occupational and physical therapy. With these treatments, his symptoms improved rapidly. He was able to stand up with support, and was able to eat by himself, albeit slowly. He was also able to make eye contact with us, although not completely smoothly. Since two weeks after the start of Memantine he has gradually become able to live his daily life calmly and without irritability. After three months, his apraxia and attention problems also started to improve.

One year after his hospitalization, his MMSE was 5/30 points and mRS was scale:4. He is now living well and preparing to be discharged to a nursing home while continuing his hospital stay. 


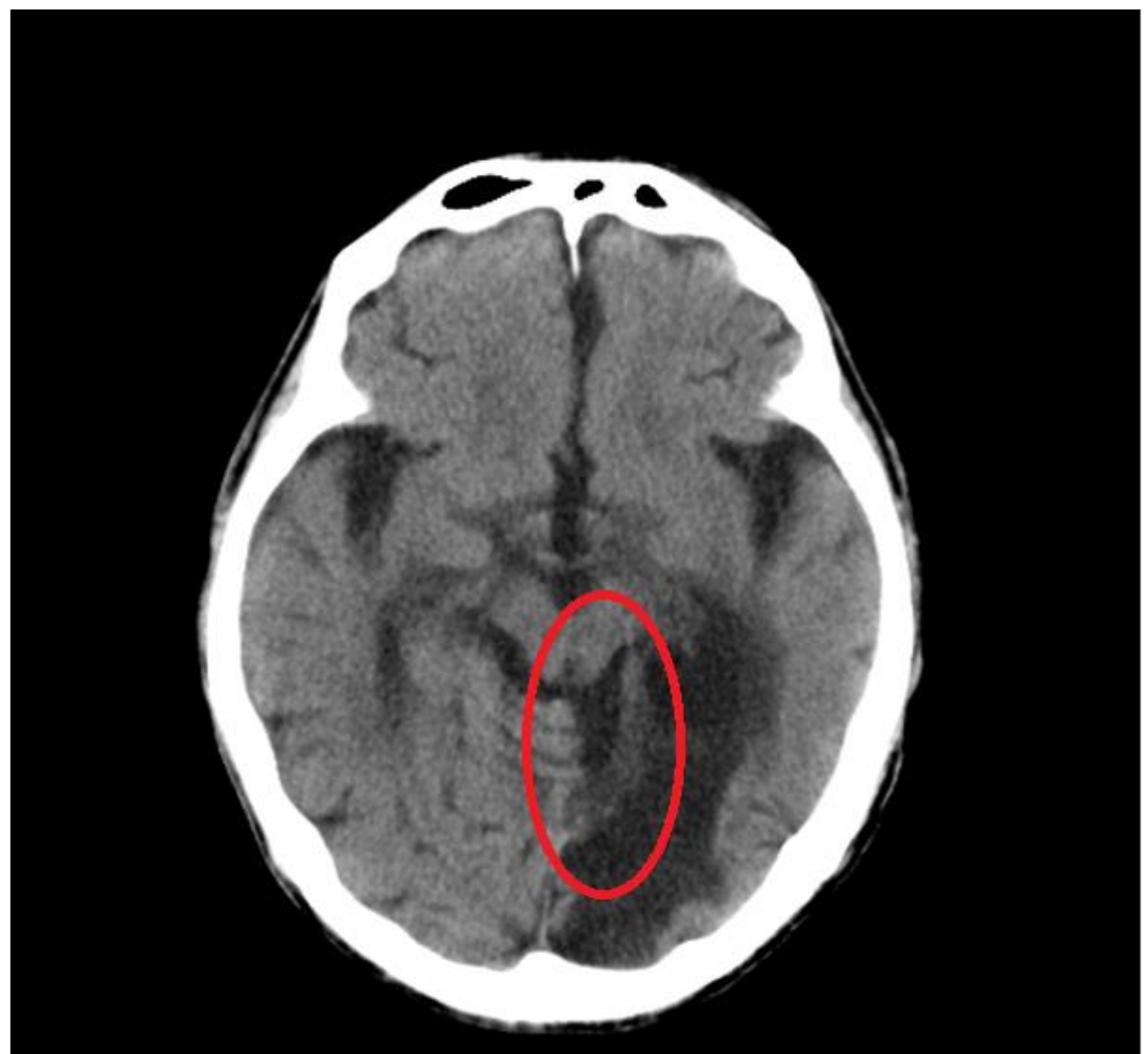

Figure 1. CT shows fibrous structures connecting the cerebellar culmen to the substantia nigra (red oval) visualized in a patient with cognitive impairment and right side paralysis.

\section{Discussion and Conclusion}

The main limitation of this case is that we were not able to perform magnetic resonance imaging (MRI) of his brain, and there are no medical records of his past treatments or medical conditions. Had they been available, we would have been able to discuss his condition and its course in more detail. Another limiting factor is the lack of scrutiny and scoring of his higher brain dysfunction.

We were unable to perform these tests because he had severe cognitive impairment. Although his cognitive functioning did not improve dramatically, it did not worsen after at least a year, which we consider to be an effect of the memantine. Memantine is a non-competitive $\mathrm{N}$-methyl-d-aspartate receptor antagonist for the treatment of Alzheimer's disease [3]. It has also been reported that memantine improves neuroplasticity, functional recovery, motor recovery, arousal, fatigue, insomnia, behavior, agitation, and cognition, as well as cognitive function. It has been reported to improve neuroplasticity, functional recovery, motor recovery, arousal, fatigue, insomnia, behavior, agitation, and cognition. 
Cerebellar culmen-substantia nigra tract assisted rehabilitation post stroke: a case report

Therefore, although not FDA approved, it may also be prescribed to patients undergoing rehabilitation after acute and chronic acquired brain injury brain injury [4]. His anger is considered to be a BPSD of dementia, and memantine may have improved this as well. What is noteworthy in this case is that after more than 10 years of separation, his paralysis improved with rehabilitation. Generally, it is better to start rehabilitation early after a stroke. If the patient's physical condition is stable, rehabilitation should be started within 24 hours after stroke, or at the latest within a week [5]. As mentioned in the introduction, we first examined genetic diversity as a reason for the effectiveness of rehabilitation for him. However, his parents had already died and he had no siblings.

Therefore, we could not investigate whether he has a specific gene that maximizes the effectiveness of post-stroke rehabilitation. Therefore, we examine from the structure of the brain that why his rehabilitation was successful.

Our hospital does not have access to MRI, but we tried to find out what we could read from the CT scan. We focused on the structure that connects the c cerebellar culmen to the substantia nigra (red oval). It is well known that the substantia nigra is one of the centers of motor control. The cerebellar culmen also has a similar role, and its disruption can lead to the appearance of parkinsonism [6].
In this case, on the contrary, it is thought that the residual pathways connecting these regions lubricated his movements and assisted his rehabilitation. Cognitive dysfunction after stroke is usually correlated with the volume of damage done. However, there are also " strategic infarct locations" that have a large impact even if the volumes are small [7]. Based on this idea, the cerebellar culmen-substantia nigra tract is one of the "strategic infarct tracts" in post-infarction rehabilitation.

\section{References}

[1] Stewart JC, Cramer SC. Genetic Variation and Neuroplasticity: Role in Rehabilitation After Stroke. J Neurol Phys Ther. 2017 Jul;41 Suppl 3(Suppl 3 IV STEP Spec Iss):S17-S23. doi: 10.1097/NPT.0000000000000180.

[2] Quinn TJ, Dawson J, Walters MR, Lees KR. Reliability of the modified Rankin Scale: a systematic review. Stroke. 2009 Oct;40(10):3393-5. doi: 10.1161/STROKEAHA.109.557256.

[3] Lu S, Nasrallah HA. The use of memantine in neuropsychiatric disorders: An overview. Ann Clin Psychiatry. 2018 Aug;30(3):234-248.

[4] Ma HM, Zafonte RD. Amantadine and memantine: a comprehensive review for acquired brain injury. Brain Inj. 2020 Feb 23;34(3):299-315. doi: 10.1080/02699052.2020.1723697.

[5] Bernhardt J, Godecke E, Johnson L, Langhorne P. Early rehabilitation after 
stroke. Curr Opin Neurol. 2017 Brazilian Journal of Case Reports. 2022

Feb;30(1):48-54. doi: Jan-Mar;02(1):24-28.

10.1097/WCO.0000000000000404.

[6] Ma X, Su W, Li S, Li C, Wang R, Chen $\mathrm{M}$, Chen H. Cerebellar atrophy in different subtypes of Parkinson's disease. J Neurol Sci. 2018 Sep 15;392:105-112. doi: 10.1016/j.jns.2018.06.027.

[7] Zhao L, Biesbroek JM, Shi L, Liu W, Kuijf HJ, Chu WW, Abrigo JM, Lee RK, Leung TW, Lau AY, Biessels GJ, Mok V, Wong A. Strategic infarct location for post-stroke cognitive impairment: A multivariate lesion-symptom mapping study. J Cereb Blood Flow Metab. 2018 Aug;38(8):1299-1311. doi: 10.1177/0271678X17728162.

Conflict of interest: The author declares no conflicts of interest associated with this manuscript. The patient has provided permission to publish these features including his examination data and imaging findings of his case, and the identity of the patient has been protected.

Acknowledgements: We thank Drs. KOBAYASHI Seiju and SHIRASAKA Tomonobu for helpful discussions and comments on the manuscript.

Funding: None.

How to cite this article: Tetsuro I, Murayama Tomonori M. Cerebellar culmen-substantia nigra tract assisted rehabilitation post stroke: a case report. 